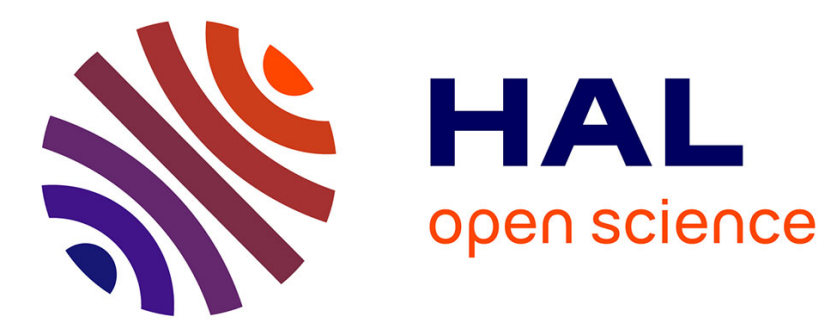

\title{
Thermo-chemical engines: Unexploited high-potential energy converters
}

Silvia Lasala, Romain Privat, Olivier Herbinet, Philippe Arpentinier, Davide Bonalumi, Jean-Noël Jaubert

\section{To cite this version:}

Silvia Lasala, Romain Privat, Olivier Herbinet, Philippe Arpentinier, Davide Bonalumi, et al.. Thermo-chemical engines: Unexploited high-potential energy converters. Energy Conversion and Management, 2021, 229, pp.113685. 10.1016/j.enconman.2020.113685 . hal-03103951

\section{HAL Id: hal-03103951 \\ https://hal.univ-lorraine.fr/hal-03103951}

Submitted on 24 Aug 2021

HAL is a multi-disciplinary open access archive for the deposit and dissemination of scientific research documents, whether they are published or not. The documents may come from teaching and research institutions in France or abroad, or from public or private research centers.
L'archive ouverte pluridisciplinaire HAL, est destinée au dépôt et à la diffusion de documents scientifiques de niveau recherche, publiés ou non, émanant des établissements d'enseignement et de recherche français ou étrangers, des laboratoires publics ou privés.

\section{(ㅇ)(1) $\$$}

Distributed under a Creative Commons Attribution - NonCommercial - NoDerivatives| 4.0 


\title{
Thermo-chemical engines: Unexploited high-potential energy converters
}

\author{
Silvia Lasala ${ }^{\mathrm{a},{ }^{*}}$, Romain Privat ${ }^{\mathrm{a}}$, Olivier Herbinet ${ }^{\mathrm{a}}$, Philippe Arpentinier ${ }^{\mathrm{b}}$, Davide Bonalumi ${ }^{\mathrm{c}}$, \\ Jean-Noël Jaubert ${ }^{\mathrm{a}}$ \\ ${ }^{a}$ Université de Lorraine, Laboratoire Réactions et Génie des Procédés, 1 rue Grandville, 54000 Nancy, France \\ ${ }^{\mathrm{b}}$ Air Liquide, Innovation Campus Paris, 1 chemin de la porte des loges, 78354 Jouy-en-Josas, France \\ c Politecnico di Milano, Dipartimento di Energia, Via Lambruschini 4, 20156 Milano, Italy
}

\section{A R T I C L E I N F O}

\section{Keywords:}

Closed power cycle

Reactive working fluid

Reaction stoichiometry

Recuperative Brayton cycle

Waste heat recovery

Renewable thermal sources

\begin{abstract}
A B S T R A C T
Thermal engines, particularly closed power cycles, are currently a focus of many studies mainly because they represent the only way to exploit renewable thermal energy. To increase the exploitation of available thermal sources, this work investigates the higher potential offered by a complementary technology based on the use of reactive working fluids instead of inert fluids: the here-called "thermo-chemical" engine. Such a power cycle enables the simultaneous conversion of thermal and chemical energy into work. Based on a theoretical approach, this paper explores engine performance considering different stoichiometries and thermodynamic characteristics of reactive fluids and different operating conditions. It is shown that the use of specific equilibrated reactions occurring in the gaseous phase might lead to extremely powerful and highly efficient energy conversion systems in the whole current domain of the application of power cycles. Moreover, it is demonstrated that, unlike classical thermal machines, a thermo-chemical engine allows efficient and powerful exploitation of lowtemperature heat sources and high-temperature cold sinks, which in general, characterize renewable thermal energy.
\end{abstract}

\section{Introduction}

Industry owes its development to the invention of the thermal engine. Currently, more than $77.7 \%[1,2]$ of the global demand for electrical power is supplied by thermal plants powered either by heat sources released from fossil and nuclear fuels $(75.0 \%)$ or by renewable thermal energy (2.7\%), such as biomass, industrial waste heat, geothermal and solar thermal power. This dominance is a result of the exclusive capability of these plants to convert heat into power. The remainder $(22.3 \%)$ represents electrical production by means of renewable technologies not involving thermal engines (solar photovoltaic, wind and hydropower), which are definitely the most rapidly growing forms of electrical power generation. A deeper analysis of those statistics reveals that thermal engines (and thus renewable thermal energies) hold a minor place $(2.7 \%)$ among the total of $25 \%$ of exploited renewable energy. Current studies [3], intended to improve the applicability of this machine in the renewable field, experience non-impactful improvements [4] and learning rates lower than those of other technologies [5].

In every conceived thermal engine, the core transformation that enables the production of useful work consists of the expansion of an inert working fluid. For example, water and air are mainly employed in steam cycles and gas turbines, respectively, to exploit combustion or nuclear (high-temperature) thermal sources [6]; additionally, a few niche applications of helium and carbon dioxide [7] in gas power cycles exist. Organic fluids, ammonia [3], and carbon dioxide [8] are also used to generate power from other lower-temperature heat sources.

This paper demonstrates that a way exists to substantially increase the currently slow improvement rate of heat engine performance, consisting of developing engines operating with reactive working fluids instead of inert ones. Such a power cycle enables the conversion of thermal energy into work by means of the simultaneous conversion of the thermal and chemical energy of a reactive energy system (the reactive working fluid). In this work, those engines have thus been labelled "thermo-chemical engines" to distinguish them from the current "thermal engines".

The conversion of chemical energy into electricity is not new: electrochemistry is the foundation of batteries, pioneered by the Italian physicists Luigi Galvani (1737-1798) and Alessandro Volta (1745-1827). The idea of converting chemical energy such as the "large

\footnotetext{
* Corresponding author.

E-mail address: silvia.lasala@univ-lorraine.fr (S. Lasala).
} 
energy change involved in dissociating gases" into work was originally suggested by Lighthill in 1957 [9]. In 1963, some colleagues of Lighthill published a paper [10] to validate his idea. These preliminary results show the first quantitative and enthusiastic effects that the use of fictive dissociating diatomic gases may have on the global efficiency of Brayton cycles, and the authors conclude that "further study with a view towards application is suggested". In 1968, another similarly optimistic study by Cheung [11] considered the same fictive fluid $\left(\mathrm{A}_{2(\mathrm{~g})} \rightleftarrows 2 \mathrm{~A}_{(\mathrm{g})}\right)$ to perform an initial screening over 7 existing reactions, leading to the selection of $\mathrm{P}_{4(\mathrm{~g})} \rightleftarrows 2 \mathrm{P}_{2(\mathrm{~g})}$. The author showed the advantageous reduction of the radiator area of a Brayton cycle operating with this reactive fluid with respect to a generic monoatomic inert gas. In 1971, Krasin and Nesterenko published a thorough review [12] of their research performed at the Nuclear Power Institute of the Academy of Science in Byelorussia. These authors found extremely favourable results on using the specific dissociating $\mathrm{N}_{2} \mathrm{O}_{4(\mathrm{~g}) /(\mathrm{l})} \rightleftarrows 2 \mathrm{NO}_{2(\mathrm{~g})} \rightleftarrows 2 \mathrm{NO}_{(\mathrm{g})}+\mathrm{O}_{2(\mathrm{~g})}$ as the working fluid for both large gas and condensing power plants. Their works revealed the highly improved heat transfer characteristics of this fluid with respect to water, carbon dioxide, helium and azote. In the same period, the Institute developed three experimental power plants operating with $\mathrm{N}_{2} \mathrm{O}_{4}$ as coolant fluid (the $100 \mathrm{~kW}-$ "Vulkan", the $1 \mathrm{MW}$-"Vikhr-1" [12] and the mobile $630 \mathrm{~kW}-$ "Pamir-630D" [13]), and validated their expected efficiency and the stable operation.

Later, some authors reconsidered $\mathrm{N}_{2} \mathrm{O}_{4}$ [14-17] for nuclear, space and solar thermal power and theoretically confirmed the highly favourable results obtained by previous researchers, while others proposed the use of $2 \mathrm{NOCl}_{(\mathrm{g})} \rightleftarrows 2 \mathrm{NO}_{(\mathrm{g})}+\mathrm{Cl}_{2(\mathrm{~g})}$ [18-21], $\mathrm{Al}_{2} \mathrm{Cl}_{6(\mathrm{~g})} \rightleftarrows 2 \mathrm{AlCl}_{3(\mathrm{~g})}$ and $\mathrm{Al}_{2} \mathrm{Br}_{6(\mathrm{~g})} \rightleftarrows 2 \mathrm{AlBr}_{3(\mathrm{~g})}[21,22]$. Depending on the considered reactive fluid, each author proved the beneficial effects of those fluids relative to traditional inert fluids.

In contrast to all previous studies on $\mathrm{N}_{2} \mathrm{O}_{4}$, recently published results $[23,24]$ do not show a real advantage underlying the use of this reactive fluid. However, calculations have been performed with commercial software not enabling the expansion or compression of reactive fluids. In the absence of a proper description from those authors, our belief is that frozen (i.e., inert) compression and expansion processes have been considered; a similar neutral result was indeed obtained in 1959 by Blander et al. [25] based on frozen expansion of dissociating aluminium chloride.

An initial outcome of this bibliographic review is that most of those studies are definitely useful for sample the break with respect to state-ofthe-art technologies but inadequate for precisely understanding and quantifying the effects of the reaction characteristics on the different thermodynamic transformations with respect to comparable inert fluids. Indeed, the comparison is always performed with respect to state-of-theart inert fluids characterised by thermodynamic properties totally different than those of the considered existing reactive fluids. The actual potential of the presence of a reaction inherent to the working fluid is thus not fully understood. Additionally, an assessment of the specific chemical effects of reactive fluids in each transformation of the fluid along the resulting thermo-chemical cycle (expansion, compression and heat exchange) is still lacking. Finally, the more extensive studies focus on a limited number of existing reactive fluids of available cycle configurations and specific applications.

To fill these gaps, this paper presents a more fundamental study enabling us to distinguish the impact of the concurrent conversion of inherent physical and chemical energy of fictive gaseous reactive fluids for which reaction characteristics have been defined considering different generalized stoichiometries and reasonable ranges of enthalpy and entropy of the reaction. For each application of the thermo-chemical engine, a very high number of fictive reactive fluids (each characterized by a specific stoichiometry and thermal characteristics) has been tested, allowing a more thorough investigation of the effects of those fluids (and thus the reaction characteristics) on the engine performances. This proposed methodology aims to provide a basic understanding of the effect of the stoichiometric and thermal features of the occurring reactions on each thermodynamic transformation shaping the power cycle (expansion, compression and heat exchange processes), as well as on the whole power cycle itself.

More precisely, this paper begins by justifying in Section 2 the use of the name "thermo-chemical engine" instead of "thermal engine" as a proper label for engines operating with reactive working fluids instead of inert ones. Then, Section 3 describes the abovementioned proposed original methodology, implemented to enable upper-level insight based on fictive reactive fluids. In Section 4, the paper analyses the advantages and drawbacks related to the use of specific reaction thermal and stoichiometric characteristics, with a focus on fluid expansion, which is the core transformation of a power production system, (in Section 4.1) and the other transformations (compression, heat exchange) as well as on the overall power cycle (in Section 4.2). This original approach not only allows the scientific understanding of the impact of using reactive fluids characterized by specific reaction characteristics but also provides the reader with a methodology to drive the selection of a proper existing reactive fluid and to define guidelines for the design of optimal configurations of thermo-chemical engines. Finally, it is shown that the choice of specific reactive working fluids may allow achievement of an unprecedented high increase in power cycles, retaining or even overtaking the highest efficiencies achievable with inert working fluids, in the whole current domain of application of power cycles.

\section{A novel concept for generating power}

Current power generation technologies are based on the alternative energy conversion schemes represented in Fig. 1. All systems consist of one or more devices in which distinct energy transformations occur, from one specific form of energy to another. In other words, no one device exists whose task is to simultaneously transform two forms of energy into another.

This paper investigates a novel scheme in which thermal and chemical energy are concurrently converted into mechanical energy, which in turn, is converted into electrically useful energy. The technology that is considered here to implement this new conversion scheme is based on the thermal engine and, in particular, the closed power cycle. Such a cycle currently realizes the steady conversion of thermal to mechanical energy through the medium of an inert fluid, which first undergoes an increase in its internal energy upon compression and heating and then expands inside a mechanical device producing useful work. In closed power cycles (the object of study of this work), the fluid exiting the turbine is cooled to the compressor inlet temperature to restart the whole cycle. The variation in the enthalpy of the fluid during its adiabatic expansion corresponds to the mechanical work collected by the mechanical device.

Consider the expansion of a reactive fluid instead of an inert one. By definition, the variation in the enthalpy of an inert fluid depends only on the change in microscopic random motion of the molecules of the system. On the other hand, the variation in the enthalpy of a reactive fluid depends not only on the change in the random kinetic energy of molecules but also on the variation in the potential chemical energy stored in their chemical bonds. The strength of this new concept lies in the positive "sum of the effects", which could result from the concurrent conversion of the physical and chemical energy of an expanding reactive fluid, fully expressed by the mathematical formulation of fluid expansion thermodynamics, as demonstrated below.

The application of the first principle of thermodynamics to an open system under steady-state conditions states that the enthalpy variation $(\mathrm{dH})$ of a fluid undergoing a thermodynamic transformation is given by the sum of the work $(\delta \mathrm{W})$ and the heat $(\delta Q)$ exchanged with the environment:

$d H=\delta W+\delta Q$

where the differential of the enthalpy for a reactive system is: 


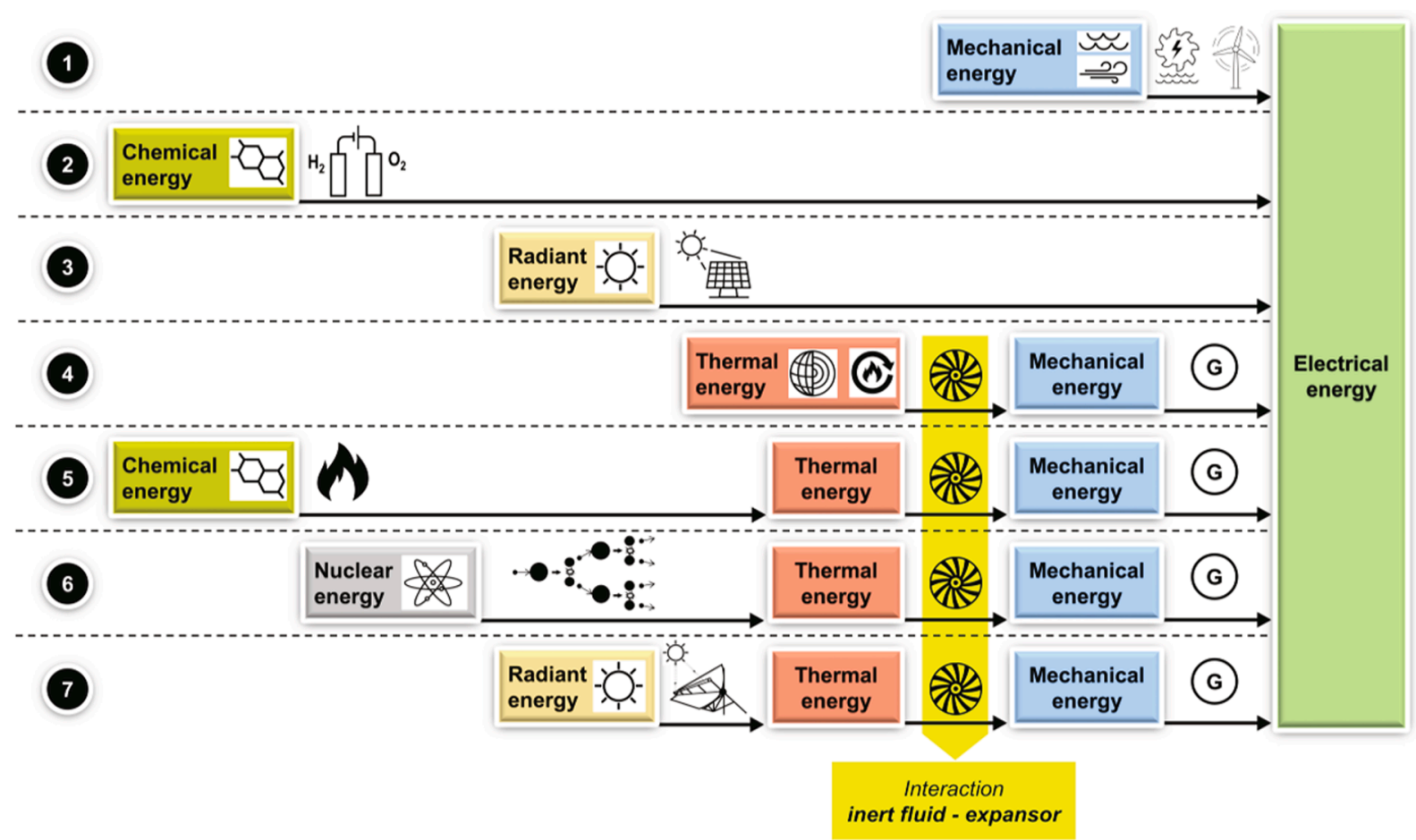

Fig. 1. Summary of the alternative energy conversion schemes on which the current technologies are based: 1) mechanical-to-electrical energy, (wind turbines, hydro-turbines, marine power technologies); 2) chemical-to-electrical energy (batteries and fuel cells); 3) radiant-to-electrical energy (photovoltaic devices); 4) thermal-to-mechanical-to-electrical energy (thermal power plants for geothermal and waste heat applications); 5) chemical-to-thermal-to-mechanical-to-electrical energy (combustion-based power plants); 6) nuclear-to-thermal-to-mechanical-to-electrical energy (nuclear power plants); 7) radiant-to-thermal-to-mechanical-toelectrical energy (solar thermal power plants). G: electrical generator (alternator).

$d H=T \cdot d S+V \cdot d P+\Delta_{R} G \cdot d \xi$

where $\mathrm{T}$ is the temperature of the system, $\mathrm{dS}$ is the entropy variation, $\mathrm{V}$ is the volume, $\mathrm{dP}$ is the pressure variation, $\Delta_{R} \mathrm{G}$ is the Gibbs energy of the reaction, and $d \xi$ is the variation in the extent of the reaction.

Furthermore, the second principle of thermodynamics for an open system under steady-state conditions states that the entropy variation of a fluid is given by:

$d S=\frac{\delta Q}{T}+\delta S_{i r r}$

where $\delta S_{\text {irr }}$ is the variation in the entropy of the stream created by the occurrence of irreversibility.

The combination of Eqs. (1)-(3) leads to the conclusion that the work that a turbine may generate from the reversible expansion $\left(\delta \mathrm{S}_{\mathrm{irr}}=0\right)$ of a reactive fluid (i.e., the maximum work, $\delta \mathrm{W}_{\text {rev }}$ ) is thus the sum of the energy variation of the fluid due to pressure variation $(\mathrm{V} \cdot \mathrm{dP}$, the inert fluid contribution) and that resulting from the chemical reaction advancement $\left(\Delta_{\mathrm{R}} \mathrm{G} \cdot \mathrm{d} \xi\right)$ :

$\delta W_{\text {rev }}=V \cdot d P+\Delta_{R} G \cdot d \xi$

\section{Methodology}

The methodology that has been implemented is presented in this section, describing the hypothesis underlying the assessed design of fictive reactive fluids (Section 3.1), the details concerning the modelling of reactive expansion and compression processes which was never presented in available literature papers (Section 3.2). A last section introduces how performances of the whole thermodynamic cycle have been calculated. It is worth noting that the methodology presented here has been implemented in codes written in Fortran language and fully developed by the authors of this paper.

\subsection{The design of reactive fluids}

An unlimited number of possible reactions exists, each characterized by its peculiar stoichiometry, thermodynamic and kinetic features. With the aim of investigating the highest reactional effect of a chemical reaction, this analysis considers infinitely fast reactions. That is, only thermodynamics governs the composition of the reactive system, and the reaction is said to be "equilibrated". Moreover, to quantify the influence of molecular dissociation (or association, in the inverse direction), gaseous working fluids at the site of generalized equilibrated single reactions were selected,

$\mathrm{A}_{\mathrm{n}(\mathrm{g})} \rightleftarrows{ }^{\mathrm{n}} / \mathrm{m} \mathrm{A}_{\mathrm{m}(\mathrm{g})}$

where the specification of the number of atoms of the two molecules, $n$ and $m$, defines the stoichiometry of the reaction.

Once the stoichiometry of the reaction is fixed, its thermal and equilibrium characteristics must be defined to finalize the reaction design. The method that has been applied to fix these characteristics is introduced below.

The studied reactive system has been modelled as a perfect gas mixture. The thermodynamic properties are thus computed accordingly [26]. Our choice for heat capacity, which is the basic property for the calculation of all other properties, is specified below. For simplicity, the specific heat capacity of each molecule has been considered constant with temperature and provided by the equipartition theorem [27]: for monoatomic molecules, $c_{\mathrm{p}, \mathrm{A}}=5 / 2 \cdot \mathrm{R}$; for diatomic molecules, $\mathrm{c}_{\mathrm{p}, \mathrm{A} 2}=7$ / $2 \cdot \mathrm{R}$; for polyatomic molecules, $\mathrm{c}_{\mathrm{p}, \mathrm{Ak}}$ (with $\mathrm{k}>2$ ) $=4 \cdot \mathrm{R}$. In this study, $\mathrm{k}=4$ is the maximum $\mathrm{k}$-value that has been considered.

Moreover, despite the reaction being at equilibrium, a conventional definition of the reactants and products is used in the paper to refer to when mentioning the thermal and advancement characteristics of the reactions. $A_{n}$ is the reactant, and $A_{m}$ is the product $\left(A_{n} \rightarrow n / m A_{m}\right)$.

As specified in the main text, the composition of the reactive mixture 
at each considered thermodynamic point is dictated only by the chemical equilibrium of the system, which corresponds to a zero-Gibbs energy of the reaction:

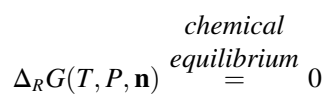

where $\mathbf{n}$ is the vector containing the molar composition of the $n_{c}$ types of molecules forming the system (in this case, the molecules are $A_{n}$ and $A_{m}$, and $n_{c}$ is thus equal to 2). It is possible to demonstrate [28] that, in the case of a perfect gas mixture, Eq. (5) corresponds to

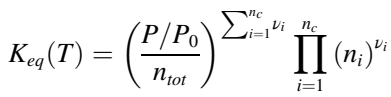

where $\mathrm{K}_{\mathrm{eq}}$ is the temperature-dependent equilibrium constant, $\mathrm{P}_{0}$ is the standard pressure ( $1 \mathrm{bar}$ ), and $\nu_{\mathrm{i}}$ is the stoichiometric coefficient of the considered i-th component involved in the reaction. The number of moles at a considered (T, P) condition can be calculated as a function of the value of the extent of the reaction at T and $\mathrm{P}, \xi(\mathrm{T}, \mathrm{P})$, and of the initial number of moles $\left(\mathrm{n}_{0}\right)$ for each $\mathrm{i}$-th component:

$n_{i}=n_{i, 0}+\nu_{i} \cdot \xi(T, P)$

In the present case, Eq. (6) corresponds to the following:

$K_{e q}(T)=\left(\frac{P / P_{0}}{n_{0, A_{n}}+n_{0, A_{m}}+\left(\frac{n}{m}-1\right) \cdot \xi(T, P)}\right)^{\frac{n}{m}-1} \cdot \frac{\left(n_{0, A_{m}}+\frac{n}{m} \cdot \xi(T, P)\right)^{\frac{n}{m}}}{n_{0, A_{n}}-\xi(T, P)}$

where the temperature-dependent formulation of the equilibrium constant for a considered reaction is given by $[26,28]$ :

$\ln K_{e q}(T)=a_{R}+\frac{b_{R}}{T}$

That is, once the reaction parameters $a_{R}$ and $b_{R}$ are fixed, under a specific (T, P) condition, the only unknown in Eq. (8) is the extent of the reaction, $\xi$. In other words, the extent of the reaction (and thus the equilibrium composition) is defined at each (T, P) condition by fixed parameters $a_{R}$ and $b_{R}$ and can be determined by means of the numerical resolution of the equation.

To assign meaningful values to $a_{R}$ and $b_{R}$, their physical meaning has been analysed and inferred from the following demonstration.

In this work, the use of the correlation in Eq. (9) is known as the Ulich approximation [29]. By combining the definitions of equilibrium constant and of Gibbs energy of reaction, one has:

$$
\left\{\begin{aligned}
\ln K_{e q}(T) & \triangleq-\frac{\Delta_{R} G^{\circ}(T)}{R T} \\
\Delta_{R} G^{\circ}(T) & \triangleq \Delta_{R} H^{\circ}(T)-T \Delta_{R} S^{\circ}(T) \\
& =\Delta_{R} H^{\circ}\left(T^{\bullet}\right)+\int_{T^{\bullet}}^{T} \Delta_{R} c_{p}^{\circ}(T) d T-T\left(\Delta_{R} S^{\circ}\left(T^{\bullet}\right)+\int_{T^{\bullet}}^{T} \frac{\Delta_{R} c_{p}^{\circ}(T)}{T} d T\right) \\
& \text { where } T^{\bullet} \text { is an arbitrary temperature. }
\end{aligned}\right.
$$

The Ulich approximation [29] states that:

$$
\int_{T^{\bullet}}^{T} \Delta_{R} c_{p}{ }^{\circ}(T) d T-T \int_{T^{\bullet}}^{T} \frac{\Delta_{R} c_{p}{ }^{\circ}(T)}{T} d T<<\Delta_{R} H^{\circ}\left(T^{\bullet}\right)-T \Delta_{R} S^{\circ}\left(T^{\bullet}\right)
$$

Hence:

$$
\ln K_{e q}(T) \approx \frac{\Delta_{R} S^{\circ}\left(T^{\bullet}\right)}{R}-\frac{\Delta_{R} H^{\circ}\left(T^{\bullet}\right)}{R} \cdot \frac{1}{T}
$$

By comparing Eq. (9) and Eq. (12), the thermodynamic interpretation of $a_{R}$ and $b_{R}$ is straightforward:
$\left\{\begin{array}{l}a_{R}=\frac{\Delta_{R} S^{\circ}\left(T^{\bullet}\right)}{R} \\ b_{R}=-\frac{\Delta_{R} H^{\circ}\left(T^{\bullet}\right)}{R}\end{array}\right.$

In this study, $\mathrm{T}^{\bullet}=298 \mathrm{~K}$ has been considered.

All considered fluids are thus gaseous mixtures of two molecules, $A_{n}$ and $A_{m}$, and the molar weight of atom $A$ is assumed to be equal to $1 \mathrm{~g} / \mathrm{mol}$. The specific composition is dictated by chemical equilibrium (infinitely fast reaction), mathematically described by the law of mass action [26] (Eq. (6) and Eq. (8)) and applicable due to the knowledge [30] of the reaction-specific equilibrium constant, $\mathrm{K}_{\mathrm{eq}}(\mathrm{T})$. The equilibrium constant characterizing a reaction can be described as a function of its standard enthalpy and entropy of reaction $\Delta_{\mathrm{R}} \mathrm{H}^{\circ}$ and $\Delta_{\mathrm{R}} \mathrm{S}^{\circ}$ at a reference temperature (denoted $\mathrm{T}^{\circ}$ ).

In addition to considering multiple stoichiometries, the parametric study accounts for a wide spectrum of possible $\left(\Delta_{R} \mathrm{H}^{\circ}, \Delta_{R} S^{\circ}\right)$ coordinates. Quantitatively, this paper investigates two reaction stoichiometries, $\mathrm{A}_{2(\mathrm{~g})} \rightleftarrows 2 \mathrm{~A}_{(\mathrm{g})}$ and $\mathrm{A}_{4(\mathrm{~g})} \rightleftarrows 4 \mathrm{~A}_{(\mathrm{g})}$, and two types of reaction design parameters (here called "reaction coordinates"), $\Delta_{\mathrm{R}} \mathrm{H}^{\circ}\left(\mathrm{T}^{\circ}\right)$ and $\Delta_{\mathrm{R}} \mathrm{S}^{\circ}\left(\mathrm{T}^{\circ}\right.$ ) (simply denoted $\Delta_{\mathrm{R}} \mathrm{H}^{\circ}$ and $\Delta_{\mathrm{R}} \mathrm{S}^{\circ}$ hereafter). Before specifying the numerical values attributed to these reaction coordinates, it is worth considering the following points.

- At a fixed temperature and pressure, the enthalpy change of the reaction under standard conditions $\left(\Delta_{\mathrm{R}} \mathrm{H}^{\circ}\right)$ is positive for endothermic reactions and negative for exothermic reactions.

- The cleavage of molecular bonds requires energy. Gaseous reactions leading to the dissociation of the reactants (i.e., to an increasing number of moles of the system) are characterized by a positive enthalpy change of the reaction under standard conditions $\left(\Delta_{\mathrm{R}} \mathrm{H}^{\circ}\right)$.

- The entropy change of the reaction under standard conditions $\left(\Delta_{\mathrm{R}} \mathrm{S}^{\circ}\right)$ indicates how the orderliness of the reacting system is affected by the reaction. For a reaction taking place in the gas phase, this value is positive when the total number of product molecules is greater than the total number of reactant molecules and negative otherwise. For a gas-phase dissociation reaction, $\Delta_{R} S^{\circ}$ is thus expected to be positive.

- An exothermic reaction in the forward direction is endothermic in the backwards direction and vice versa. Similarly, if the positive entropy change is positive in the forward direction, it is negative in the backwards direction and vice versa.

In this study, the specific values of $\Delta_{R} H^{\circ}$ and $\Delta_{R} S^{\circ}$ have been fixed referring to the direction leading to an increasing number of moles. On the basis of the above points, $\Delta_{R} \mathrm{H}^{\circ}$ and $\Delta_{R} S^{\circ}$ can only be positive. According to the observation of reaction parameters of existing reactions, it has been agreed to vary $\Delta_{\mathrm{R}} \mathrm{H}^{\circ}$ between $0 \mathrm{~kJ} / \mathrm{mol}$ and $200 \mathrm{~kJ} / \mathrm{mol}$ and $\Delta_{\mathrm{R}} \mathrm{S}^{\circ}$ between $0 \mathrm{~kJ} /(\mathrm{mol} \cdot \mathrm{K})$ and $0.2 \mathrm{~kJ} /(\mathrm{mol} \cdot \mathrm{K})$.

\subsection{Modelling the expansion and compression of a reactive fluid}

The expansion and compression processes have been considered adiabatic $(\delta Q=0)$ and reversible $\left(\delta S_{\text {irr }}=0\right)$. Hence, from Eq. (3), the two transformations are isentropic. Moreover, chemical equilibrium has been assumed at each thermodynamic state, meaning that Eq. (5) applies to each point along the transformation.

In general, when considering the expansion and compression of a fluid, the inlet temperature, pressure and outlet pressure are known. The outlet temperature is a priori unknown. Considering the abovementioned assumptions, the composition of the reactive fluid is at each point dictated by equilibrium, which depends on the temperature and pressure of the system. Therefore, the inlet composition is known, while the outlet composition is a priori unknown, as it is a function of the unknown temperature.

To determine the outlet temperature - and thus the composition and 
the other thermodynamic properties - an iterative process has been established, in which the outlet temperature was varied to ensure the invariance of fluid entropy between the inlet and the outlet of the transformation:

$S\left(T_{\text {in }}, P_{\text {in }}, \mathbf{n}_{\text {equil. at }\left(T_{\text {in }}, P_{\text {in }}\right)}\right)-S\left(T_{\text {out }}, P_{\text {out }}, \mathbf{n}_{\text {equil. at }\left(T_{\text {out }}, P_{\text {out }}\right)} \stackrel{\text { isentropic }}{\text { process }} \stackrel{=}{=} 0\right.$

The knowledge of thermodynamic properties at the inlet and outlet conditions enables the calculation of both expansion and compression work.

\subsection{Determination of cycle performances}

In this investigation, the Brayton power cycle has been investigated. To characterize its performance, the produced net work, $\mathrm{W}_{\text {net }}$, has been calculated from the knowledge of expansion and compression works, $\mathrm{W}_{\text {exp. }}$ and $\mathrm{W}_{\text {compr. }}$ :

$W_{\text {net }}=W_{\text {exp. }}-W_{\text {compr. }}$

and the efficiency,

$\eta=\frac{W_{\text {net }}}{Q_{\text {in }}}$

where $Q_{\text {in }}$ is the thermal energy provided to the cycle by the exploited thermal source. In the case of negative net work, the efficiency has been set to zero.

Heat exchangers have been considered adiabatic, and the composition has been assumed to follow chemical equilibrium at each point.

In this work, two configurations of a Brayton cycle have been analysed: simple and recuperative configurations. In particular, in the case of a positive difference between the temperature at the turbine outlet and that at the compressor outlet, the -more convenient- recuperative configuration has been applied instead of the simple one. Regarding the simple cycle, the heat input $\left(Q_{i n}\right.$, here $\left.Q_{i n, s}\right)$ has been calculated as the total thermal energy required to heat the fluid from the compressor outlet to the turbine inlet. In the recuperative configuration, the heat input $\left(Q_{i n}\right.$, here $\left.Q_{i n, r}\right)$ has been determined as the difference between such an overall thermal energy $\left(Q_{\text {in,s }}\right)$ and that provided by the recuperative heat exchange between the hot stream exiting the turbine and the cold stream exiting the compressor $\left(\mathrm{Q}_{\mathrm{rec}}\right)$ :

$Q_{i n, r}=Q_{i n, s}-Q_{r e c}$

In particular, $\mathrm{Q}_{\mathrm{rec}}$ has been considered equal to the maximum thermal power that could be exchanged between the two low-pressure and high-pressure streams, which is equivalent to assuming a unitary heat exchanger effectiveness [31]:

$Q_{\text {rec }}=\min \left\{Q_{\max , P_{\min }} ; Q_{\max , P_{\max }}\right\}$

where $Q_{\max }$, Pmin is the thermal energy that would be exchanged if the fluid at minimum pressure (the hot fluid) cools as much as possible (from the turbine outlet temperature to the compressor outlet temperature) and $Q_{\max }$, Pmax is the thermal energy that would be exchanged if the fluid at maximum pressure (the cold fluid) heats as much as possible (from the compressor outlet temperature to the turbine outlet temperature).

\section{Results and discussion}

\subsection{The expansion of reactive fluids}

The expansion of a working fluid is the central process of any thermal engine. Indeed, the sole turbine (i.e., without the engine's other components) is able to convert the energy content of any available pressurized fluid into mechanical energy. The first step of the study intends to provide an understanding of the impact of reactive fluid features on the power generated by its expansion in a turbine.

Different reactive fluids have been considered, according to the parametric methodology outlined in Section 3.2 (i.e., each one characterized by a specific stoichiometry, $\Delta_{\mathrm{R}} \mathrm{S}^{\circ}$ and $\Delta_{\mathrm{R}} \mathrm{H}^{\circ}$ ). The expansion of each of these fluids from a specific inlet pressure and temperature to a specific outlet pressure has been computed and recorded in specific maps, as outlined below. In particular, the compositional variation during expansion, outlet temperature and generated work have been calculated, as detailed in Sections 3.2 and 3.3, and reported into three respective maps as a function of the reaction coordinates, $\Delta_{R} S^{\circ}$ and $\Delta_{\mathrm{R}} \mathrm{H}^{\circ}$. The maps in Fig. 2 represent these quantities for fluids of stoichiometry $\mathrm{A}_{2} \rightleftarrows 2 \mathrm{~A}$ under fixed operating conditions (turbine inlet temperature and pressure fixed at $700 \mathrm{~K}$ and 3 bar, turbine outlet pressure equal to $1 \mathrm{bar}$ ). These conditions represent the starting point for our discussion. Indeed, $700 \mathrm{~K}$ characterizes widely available mediumtemperature heat sources currently exploitable only by cost-intensive technologies based on the use of inorganic inert fluids, 3 bar is a challenging low inlet pressure that is highly desirable in the safest power generation applications, and 1 bar is an outlet pressure that could be achieved by an expansion characterized by a rather low pressure ratio (defined as the maximum pressure divided by the minimum pressure) equal to 3. The effect of the modification of these operating conditions is also discussed in this paper.

Fig. 2a reveals an inlet composition consisting of almost $100 \%$ reactants in the region characterized by high $\Delta_{\mathrm{R}} \mathrm{H}^{\circ}$ and low $\Delta_{\mathrm{R}} \mathrm{S}^{\circ}$ and $100 \%$ products in the region characterized by low $\Delta_{\mathrm{R}} \mathrm{H}^{\circ}$ and high $\Delta_{\mathrm{R}} \mathrm{S}^{\circ}$. In these two regions, the couples of reaction coordinates $\Delta_{\mathrm{R}} \mathrm{H}^{\circ}$ and $\Delta_{\mathrm{R}} \mathrm{S}^{\circ}$ entail extremely low and high values of the equilibrium constant, respectively, at the turbine inlet temperature. The extreme values of the equilibrium constant characterizing those regions self-explain the negligible observed reaction shift driven by decreasing pressure and temperature during adiabatic expansion (Fig. 2b).

Conversely, at intermediate $\Delta_{\mathrm{R}} \mathrm{H}^{\circ}$ and $\Delta_{\mathrm{R}} \mathrm{S}^{\circ}$ values, the inlet equilibrium composition is highly sensitive to the selection of different reaction parameters. Moreover, Fig. $2 \mathrm{~b}$ shows that such a region identifies fluids as a site of significant variations in the total number of moles of the system (and thus the composition) during adiabatic expansion.

To explain this behaviour, let us recall some thermodynamic principles stating that both temperature and pressure variation (occurring during a typical expansion process) have an effect on the evolution of the dissociation/association reactions [28]. The law of mass action states that for a reaction conducted at a fixed temperature and pressure, a decrease in the specified pressure (at constant temperature) shifts the equilibrium in the direction that increases the number of moles, that is, the forward direction for reaction $\mathrm{A}_{2(\mathrm{~g})} \rightleftarrows 2 \mathrm{~A}_{(\mathrm{g})}$ (i.e., $\mathrm{A}_{2(\mathrm{~g})} \rightarrow 2 \mathrm{~A}_{(\mathrm{g})}$ ). On the other hand, according to the van't Hoff equation [32], when an equilibrated reaction is conducted at a fixed temperature and pressure, decreasing the specified temperature (at constant pressure) implies a shift of equilibrium in the exothermic direction $\left(\Delta_{\mathrm{R}} \mathrm{H}^{\circ}<0\right)$. Considering the gaseous reaction $\mathrm{A}_{2(\mathrm{~g})} \rightleftarrows 2 \mathrm{~A}_{(\mathrm{g})}$, which is inevitably endothermic in the forward direction and exothermic in the backward direction, the reduction in temperature thus shifts the equilibrium in the backward direction. However, the pressure and temperature vary simultaneously during an adiabatic expansion process, and the final evolution of the reaction is not straightforward by simple reasoning regarding the two separate effects. In fact, it is worth noting that the pressure change, temperature change and reaction shift during adiabatic expansion are all interrelated and depend on the reaction coordinate.

Conversely, the observation in Fig. $2 b$ and Fig. $2 d$ reveals that reactive fluids that generate much greater work than inert fluids (either reactants or products) are identified by the reaction coordinate, allowing the reaction to take place during expansion. More specifically, the difference between the highest work achievable by expanding the considered reactive fluids and that resulting from the expansion of pure 


\section{a)}
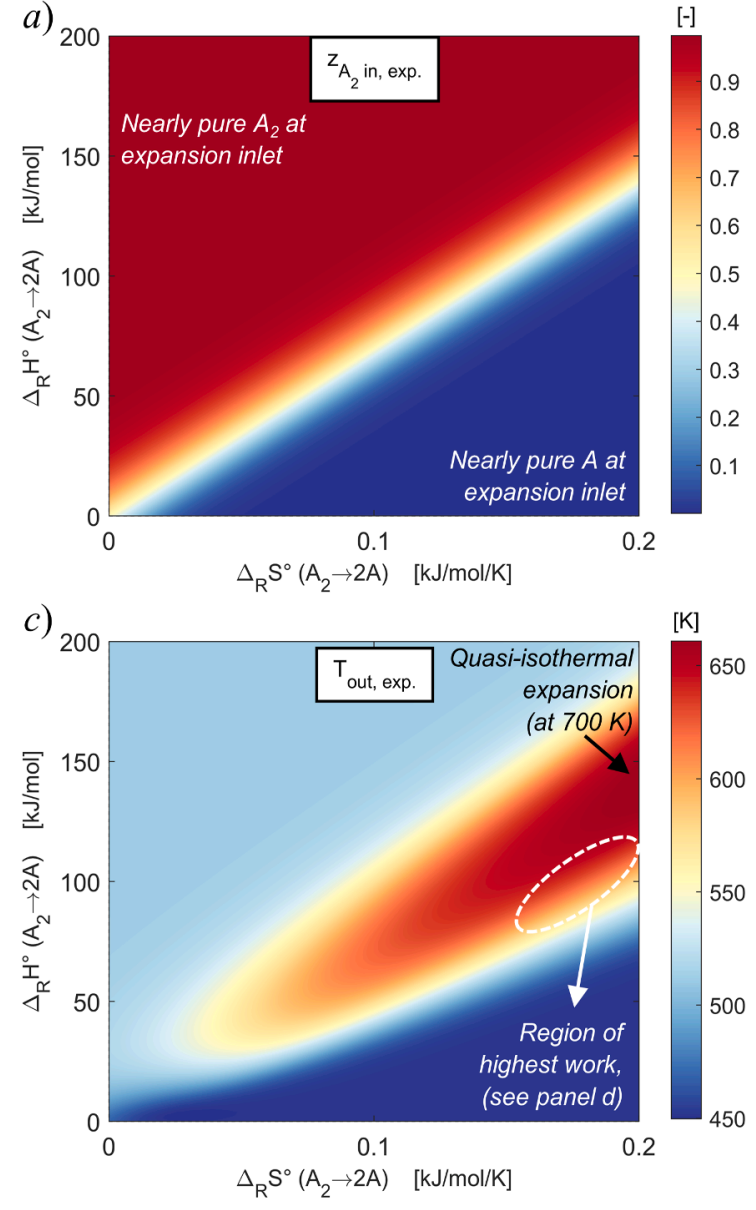
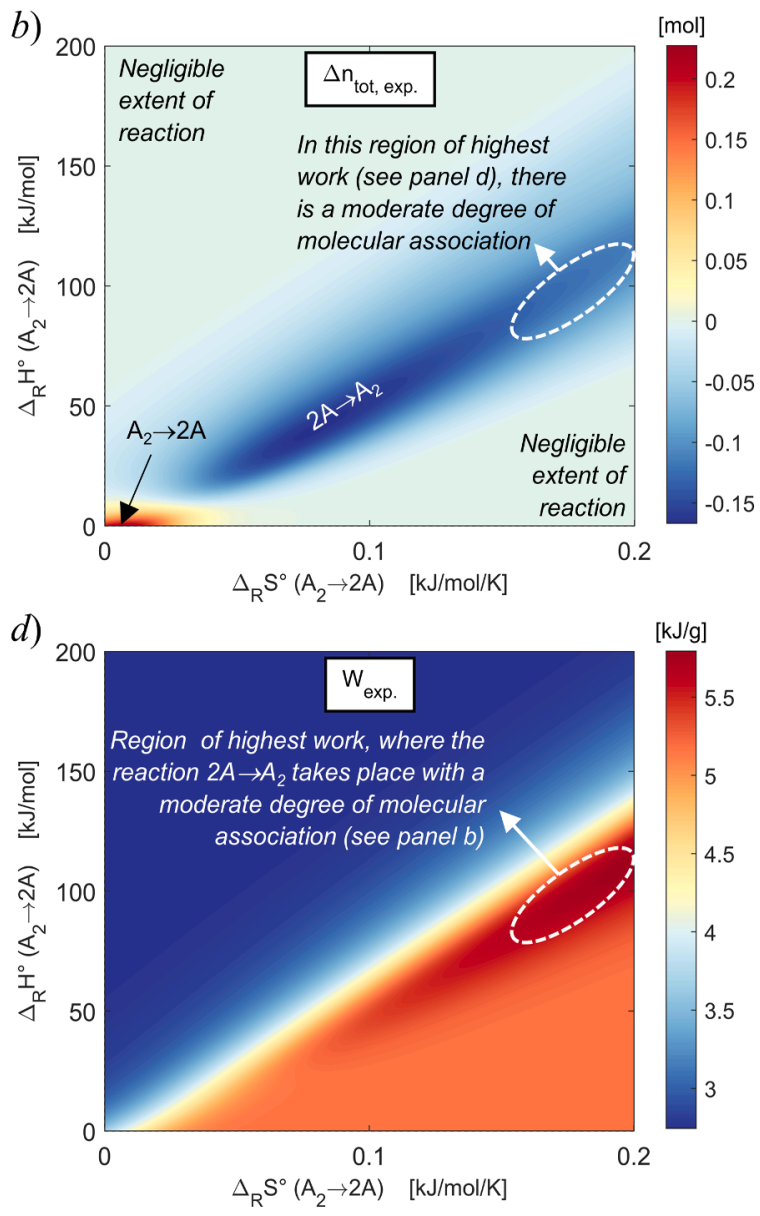

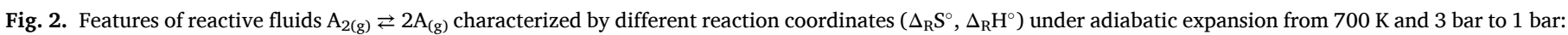

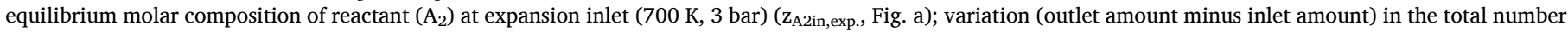

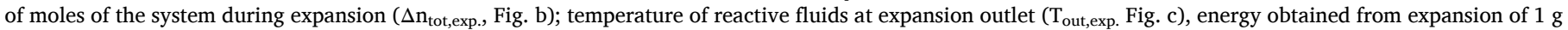
of fluid ( $W_{\text {exp. }}$ Fig. d).

product (molecule A) is $+14 \%$ of pure product work. The relative difference between the same most powerful reactive fluid and the pure reactant (molecule $A_{2}$ ) is $+115 \%$. In summary, Fig. $2 \mathrm{~b}$ highlights that either there is no reaction shift during adiabatic expansion (the fluid behaves as an inert fluid) or the exothermic reaction $\left(2 \mathrm{~A}_{(\mathrm{g})} \rightarrow \mathrm{A}_{2(\mathrm{~g})}\right)$ takes place. During the expansion, a pressure decrease favours the (endothermic) forward reaction $\left(\mathrm{A}_{2(\mathrm{~g})} \rightarrow 2 \mathrm{~A}_{(\mathrm{g})}\right)$, while a temperature decrease favours the (exothermic) backward reaction $\left(2 \mathrm{~A}_{(\mathrm{g})} \rightarrow \mathrm{A}_{2(\mathrm{~g})}\right)$. It can thus be concluded that among these two antagonistic effects, temperature effects are dominant.

Furthermore, it is recalled that the expansion of simpler and lighter fluids leads to more generated work $[6,33]$ (in other words, a low "molecular complexity" is preferred). Accordingly, Fig. 2b and Fig. 2d reveal that the region of highest work is the region characterized by a moderate degree of reaction shift from simple and lighter molecules $\left(\mathrm{A}_{(\mathrm{g})}\right)$ to complex and heavy molecules $\left(\mathrm{A}_{2(\mathrm{~g})}\right)$. Therefore, the effect of the molecular complexity is antagonistic to the temperature effect previously mentioned, which favours the exothermic reaction and thus the formation of $\mathrm{A}_{2(\mathrm{~g})}$. Overall, it is possible to claim that the most work is obtained when the exothermic reaction occurs but with a moderate reaction shift to limit the formation of $\mathrm{A}_{2(\mathrm{~g})}$ (and thus the increase in molecular complexity). As illustrated in Fig. 2c, the exothermal character of the reaction tends to annihilate the temperature decrease (see the quasi-isothermal region) during adiabatic expansion. The highest work is obtained for a moderate reaction shift and thus for a moderate reduction of the temperature decrease.
Considering a pressure ratio equal to 3 (regardless of the inlet pressure), a turbine inlet temperature ranging between $400 \mathrm{~K}$ and $1000 \mathrm{~K}$ and an outlet temperature equal to $300 \mathrm{~K}$, the use of gaseous reactive fluids characterized by the stoichiometry $\mathrm{A}_{2(\mathrm{~g})} \rightleftarrows 2 \mathrm{~A}_{(\mathrm{g})}$ always leads to an increase in the generated power to approximately $14 \%$ more (in terms of relative difference) than the inert fluid, which leads to the highest value of turbine work. Increasing the pressure ratio enables the enhancement of such a power increase. Moreover, the use of a fluid leading to a higher molecular association during expansion (for example, being characterized by the stoichiometry $\mathrm{A}_{4(\mathrm{~g})} \rightleftarrows 4 \mathrm{~A}_{(\mathrm{g})}$ ) entails an increased power output almost proportional to the increase in the degree of molecular association (e.g., the doubled reaction $\mathrm{A}_{4} \rightleftarrows 4 \mathrm{~A}$ is considered instead of $\mathrm{A}_{2} \rightleftarrows 2 \mathrm{~A}$ ).

On the other hand, variation in the inlet pressure (for example, from 1 bar to 50 bar) at a constant pressure ratio leads to a negligible modification of the maximum attainable power and to a slight shift of the highest-work region on the plane $\Delta_{R} H^{\circ}-\Delta_{R} S^{\circ}$.

\subsection{Net power of reactive closed power cycles}

The global effect of using reactive fluids in a power cycle has been assessed in this work considering a closed Brayton cycle (see Fig. 2a). In this application, a gaseous fluid is cyclically compressed to a specific higher pressure, heated by the reception of the available thermal energy, expanded inside a turbine -thus producing useful work- and cooled to the compressor inlet temperature to restart the cycle. The objective of 
this section is to analyse the impact on net power resulting from the adoption of reactive fluids rather than inert fluids.

Net power $\left(\mathrm{W}_{\text {net }}\right)$ is the power produced by expansion and reduced by the power required for compression. In Section 4.1, the full advantage resulting from the expansion of properly selected reactive working fluids has been quantified. To evaluate the net power, a preliminary investigation of the compression process is needed. Fig. 3 presents the results for the compression of reactive fluids, considering the same inlet and outlet pressures as the expansion previously assessed and an inlet temperature equal to $300 \mathrm{~K}$. The pressure and temperature changes resulting from compression mainly entail a shift of the equilibrium in the endothermic direction (Fig. 3b), thus implying an almost isothermal compression (Fig. 3c) and demanding less energy than inert fluids to increase the pressure of the system (Fig. 3d).

In summary, the adiabatic compression process involving a reacting fluid is symmetrical to the adiabatic expansion: (i) either the endothermic reaction takes place or the fluid behaves as an inert fluid; (ii) temperature effects are dominant in the endothermic reaction, which produces compounds of low molecular complexity; and (iii) as an antagonistic effect, a higher molecular complexity favours a lower compression work. The lowest compression work is thus obtained for a moderate shift of the endothermic reaction.

A joint examination of Fig. $2 \mathrm{~d}$ and Fig. $3 \mathrm{~d}$ reveals the well-known cause limiting the net power attainable from Brayton cycles operating with any inert working fluid: the use of more complex (i.e., having more atoms) and heavier molecules, such as pure $A_{2}$ instead of pure $A$,
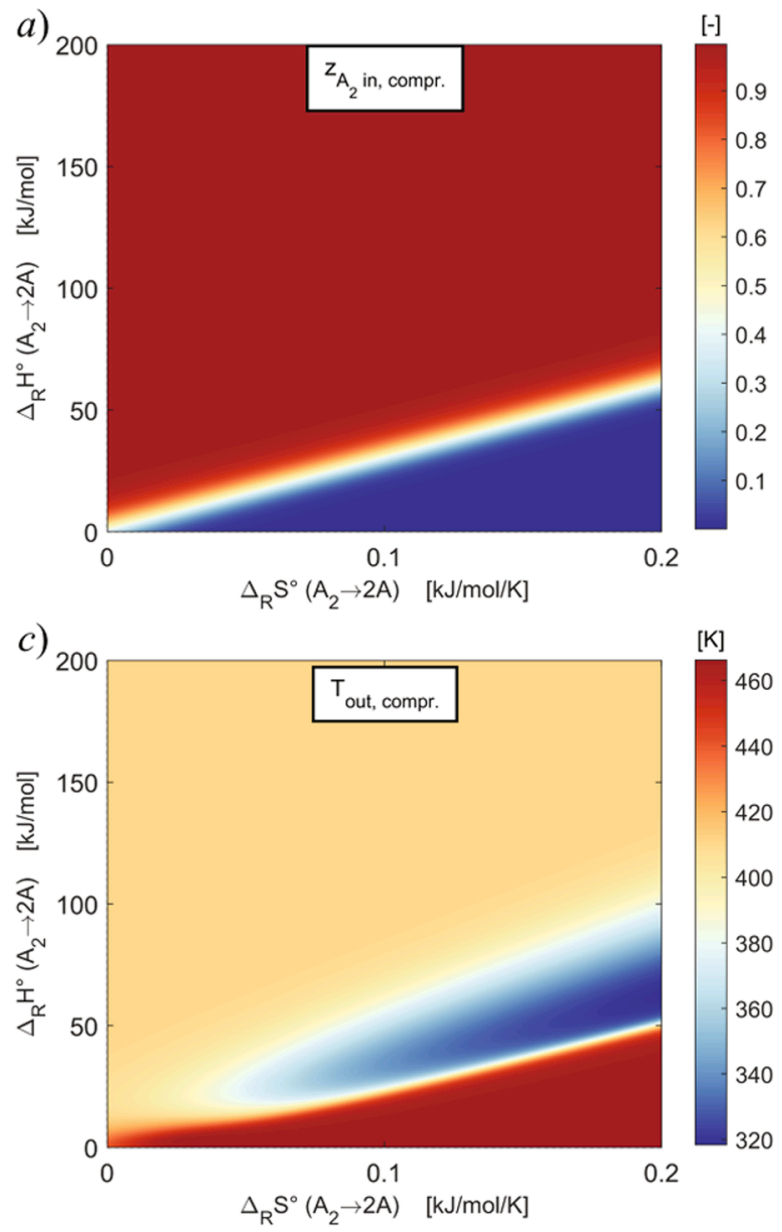

minimizes both expansion work (unfavourable effect) and compression work (favourable effect); conversely, the selection of simpler and lighter fluids, such as pure $A$ instead of pure $A_{2}$, maximizes both expansion work (favourable effect) and compression work (unfavourable effect).

The striking power of using specific reactive fluids lies in their singular capability to enable the simultaneous maximization of expansion work (Fig. 2d) and minimization of compression work (Fig. 3d). The use of reactive fluids whose reaction coordinates entail the occurrence of a reaction during expansion always leads to an exceptional increase in net power (with respect to comparable gaseous pure fluids). This is shown in Fig. 4 for two different stoichiometries $\left(\mathrm{A}_{2(\mathrm{~g})} \rightleftarrows 2 \mathrm{~A}_{(\mathrm{g})}\right.$ in Fig. $4 \mathrm{a}$ and $\mathrm{A}_{4(\mathrm{~g})} \rightleftarrows 4 \mathrm{~A}_{(\mathrm{g})}$ in Fig. $4 \mathrm{~b}$ ). In the treated example (Fig. 4a), the net power obtained by a Brayton cycle working with reactive fluids (approximately $4.1 \mathrm{~kJ} / \mathrm{g}$ ) is increased by more than $140 \%$ with respect to that of the pure products $((4.1-1.7) / 1.7 \cdot 100=141 \%)$ and by more than $270 \%$ with respect to that of the pure reactants. Moreover, it has been proven that such an increase is most enhanced at lower maximum temperatures of the cycle and at higher pressure ratios (both shown in Section 4.4). A comparison of Fig. 4a and Fig. 4b shows that the use of more dissociative stoichiometries entails only a slight increase in net power.

\subsection{Efficiency of reactive closed power cycles}

The efficiency of power cycles ( $\eta$ ) is calculated as the ratio between the net work (the valuable output) and the input thermal power supplied
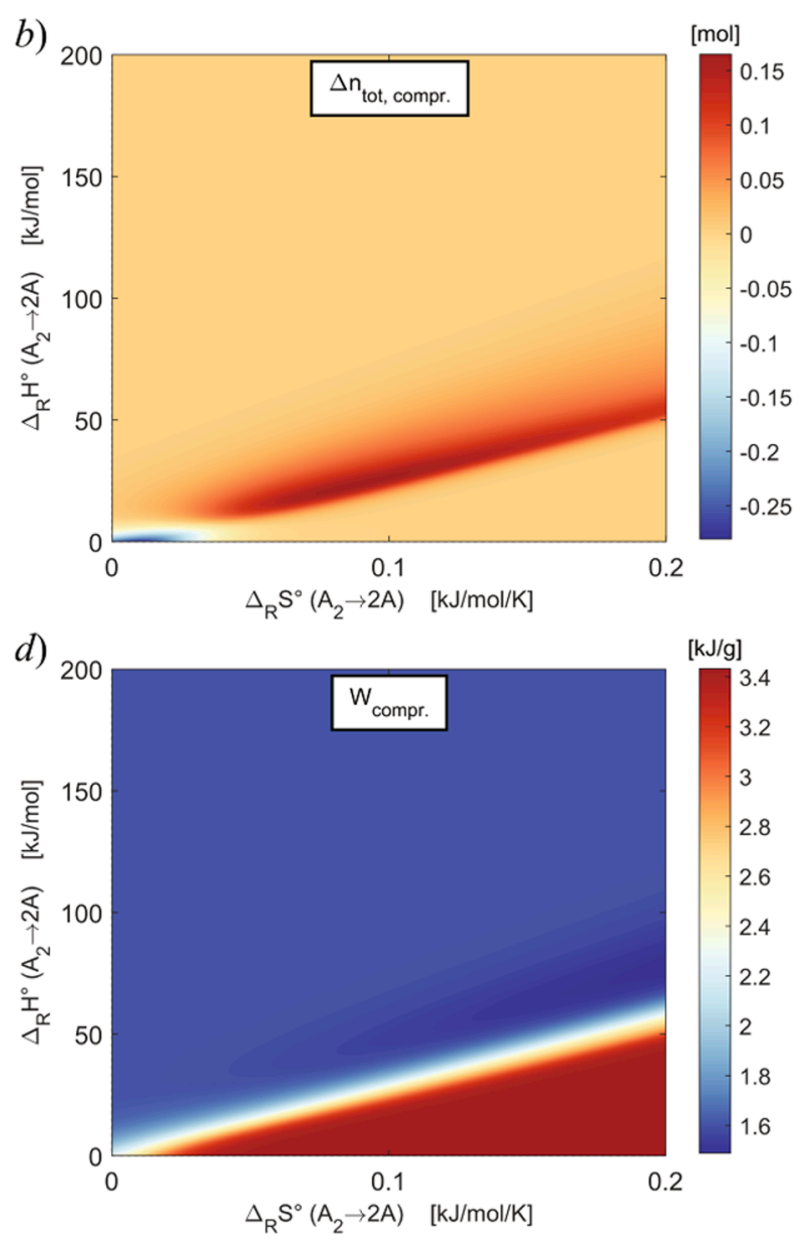

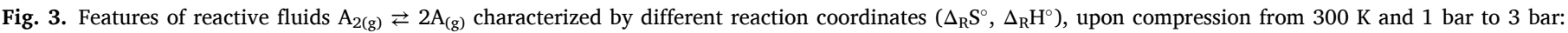

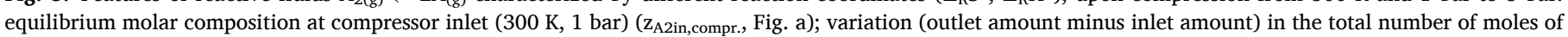

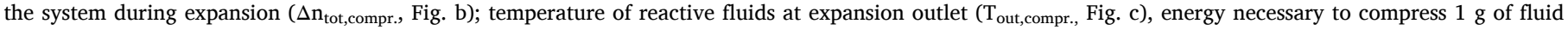
(W $\mathrm{W}_{\text {compr., }}$ Fig. d). 

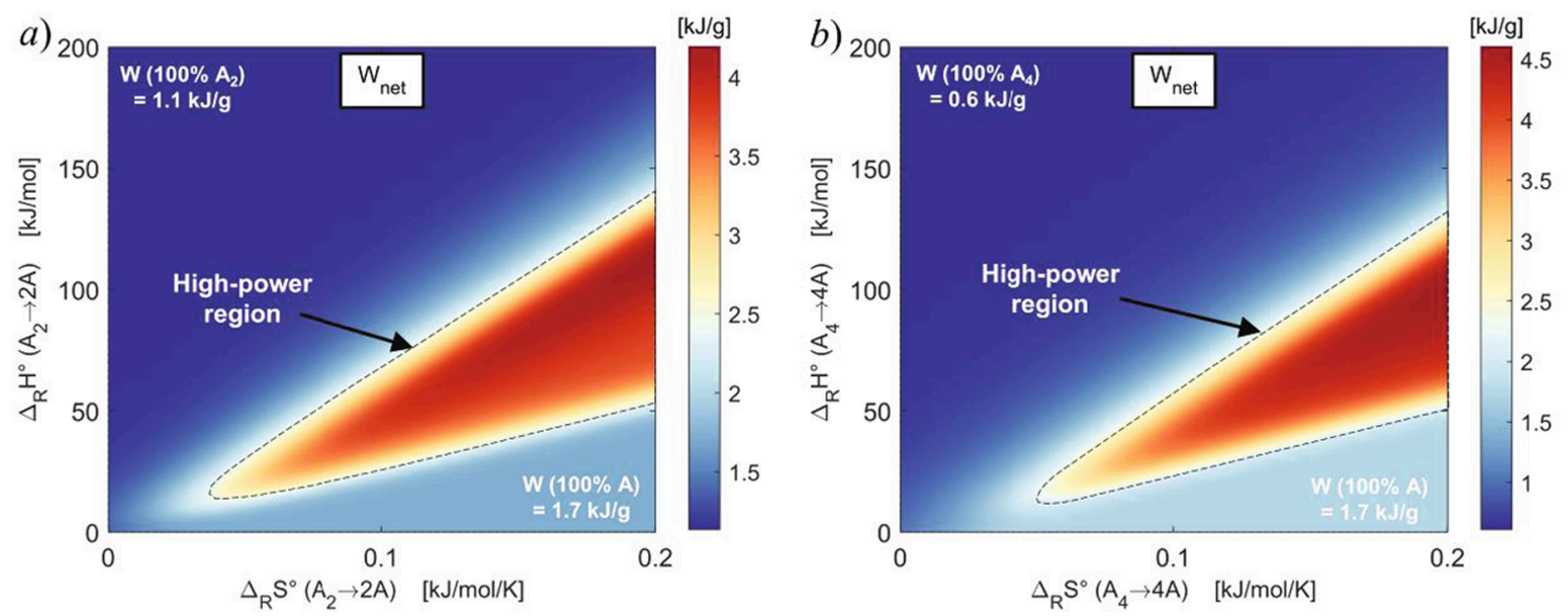

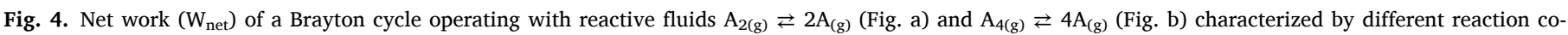

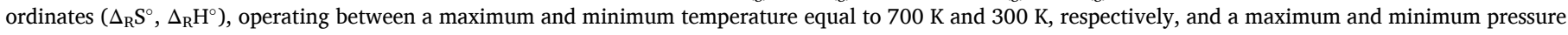
equal to 3 bar and 1 bar, respectively.

by the external exploited source [34]. The evaluation of cycle efficiency thus needs the additional consideration of the effect of heating reactive fluids in isobaric heat exchangers.

The aforementioned effects explained by the van't Hoff equation indicate that the increase in the isobaric temperature of a reactive fluid shifts the reaction equilibrium towards the endothermic direction. Herein lies the drawback of using reactive working fluids: a higher input thermal energy is always required for the power cycle, which negatively affects its efficiency.

However, such a drawback can be partially counterbalanced by the addition of a recuperator (see Fig. 5a). Indeed, when the temperature of an equilibrated reactive fluid is reduced in the cooling heat exchanger, the reaction proceeds in the exothermic direction, thus releasing a far greater amount of thermal energy. This observation suggests the favourable possibility of recycling such otherwise wasted thermal energy to pre-heat the reactive fluid entering the primary heat exchanger and reduce heat input provided by the external source. Certainly, in a counter-current recuperator, the heat transfer process is possible as long as the temperature of the hot stream (exiting the turbine) is greater than the temperature of the cold stream (exiting the compressor). In standard inert-fluid cycles, such a necessary condition limits the favourable use of a recuperator because the fluid under expansion or compression cools and heats substantially. Instead, as previously proven in Sections 4.1 and
4.2, the use of reactive fluids enables the establishment of isothermal (or heated) expansions and isothermal (or cooled) compressions. Hence, the domain of application of recuperative cycles is by far larger for reactive fluids than for inert fluids (see Fig. 5b).

Depending on the considered couples of reaction coordinates, the use of reactive fluids may lead to higher, comparable or lower efficiencies with respect to the pure fluids. Fig. 6a, together with Table 1 and the previously presented Fig. 4a, provides a quantification of efficiency and power relative to comparable pure fluids, considering an engine operating between $300 \mathrm{~K}$ and $700 \mathrm{~K}$ and a selected pressure ratio equal to 3 . To present the analysis that follows, some fluids have been selected and then named as being representative of the different regions of Fig. $6 \mathrm{a}$. The percent values reported hereinafter are relative differences, as specified in Table 1.

- As shown in Fig. 4, reactive fluids lead to extremely higher power with respect to pure fluids; that is, considering all the points A-F indicated in Fig. 6a, the average increase in net work is $+79 \%$ for cycles working with pure products (molecule A) and $+177 \%$ for cycles working with pure reactants (molecule $A_{2}$ ).

- Reactive fluids leading to the highest efficiency (for example, fluid F), which is $9 \%$ higher than that attainable with the use of the most efficient pure fluid (molecule $\mathrm{A}_{2}$ ), are characterized by the lowest a)

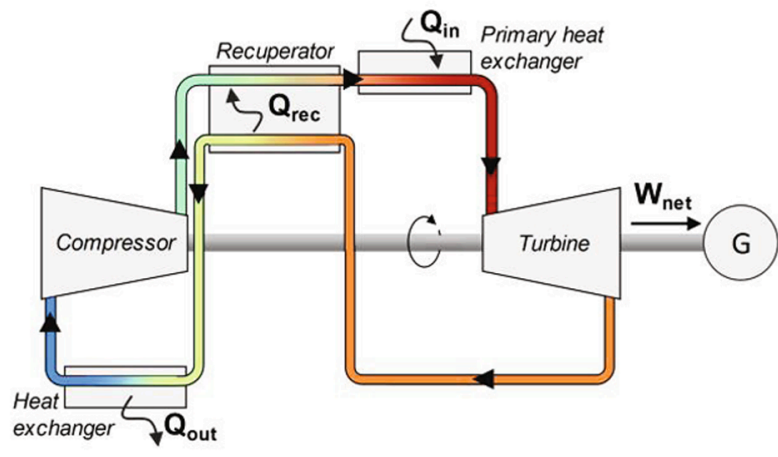

b)

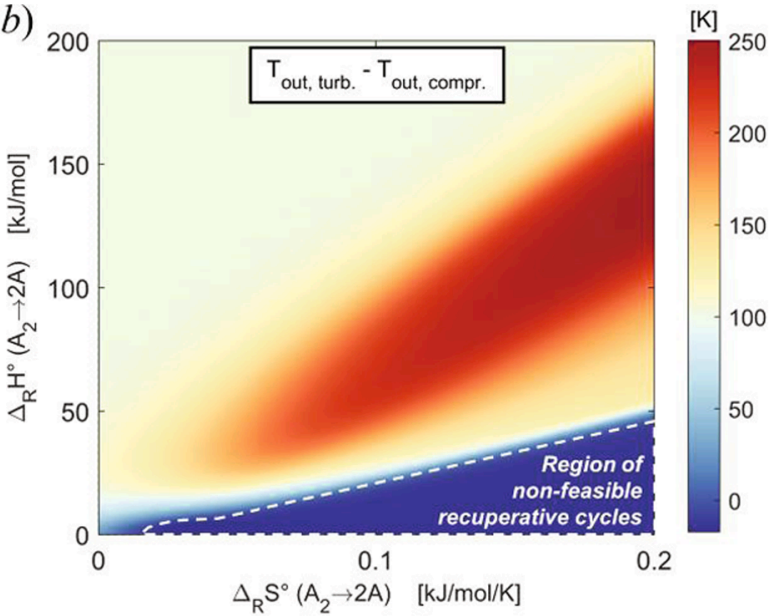

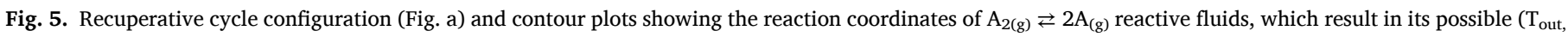
turbine $\mathrm{T}_{\text {out,compressor }}>0$ ) or impossible $\left(\mathrm{T}_{\text {out,turbine }}-\mathrm{T}_{\text {out,compressor }}<0\right.$ ) applicability (Fig. b). 


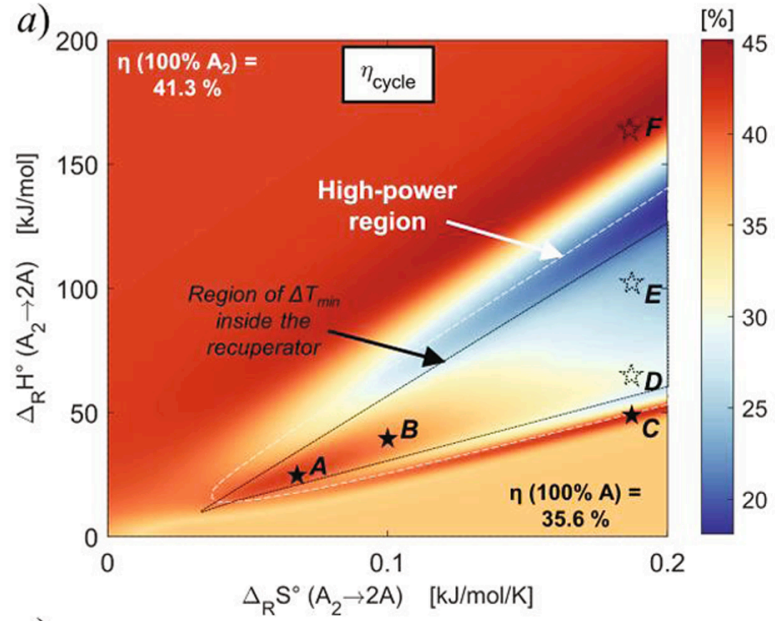

c)

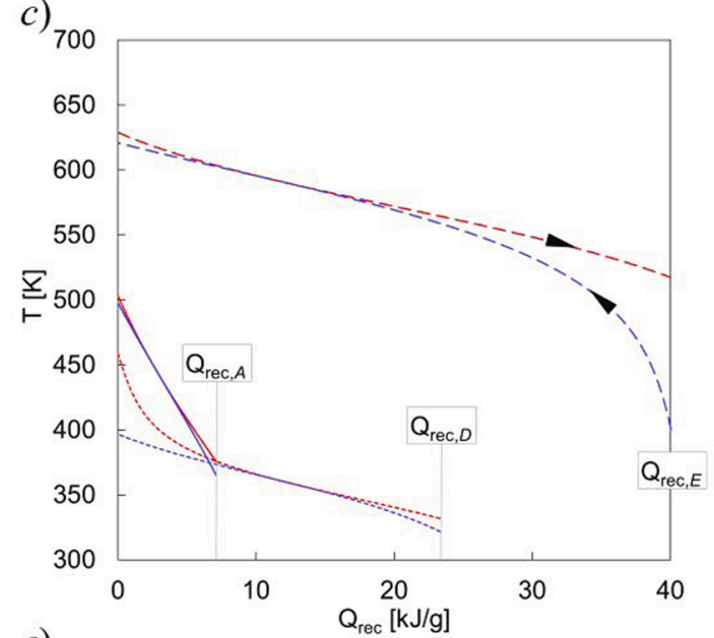

e)

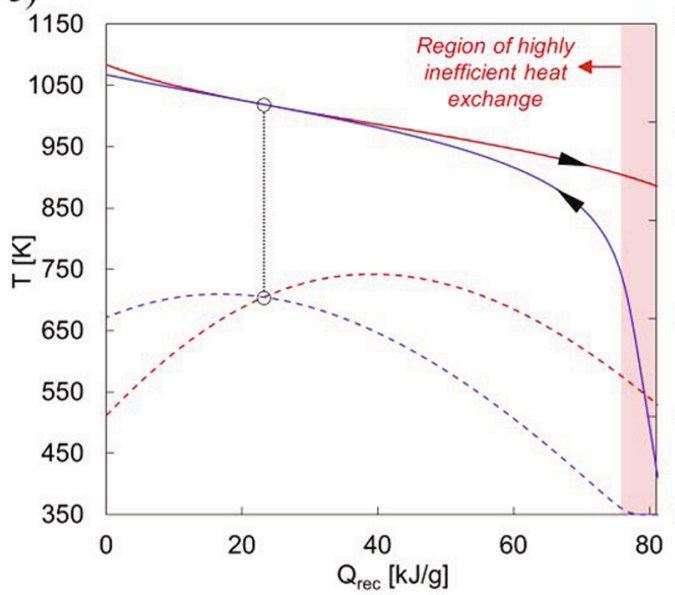

0.010

0.008

0.002

0.000

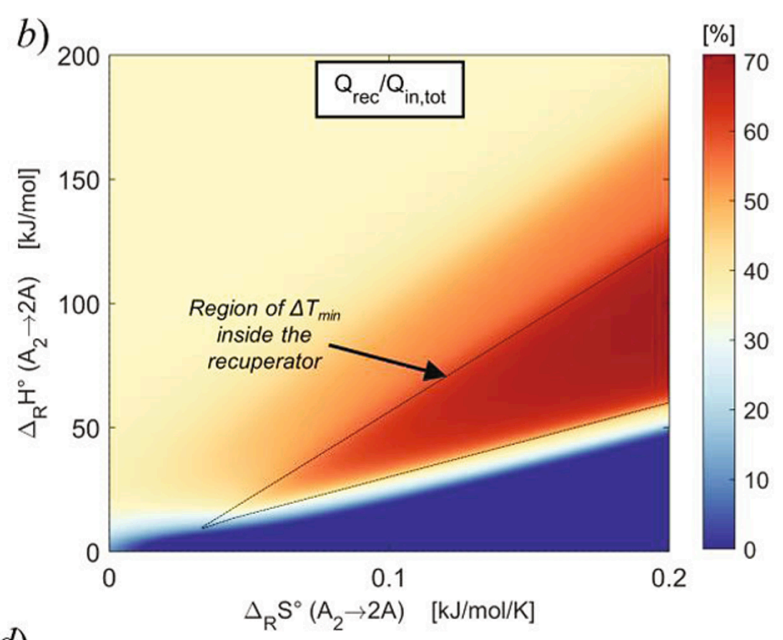

d)

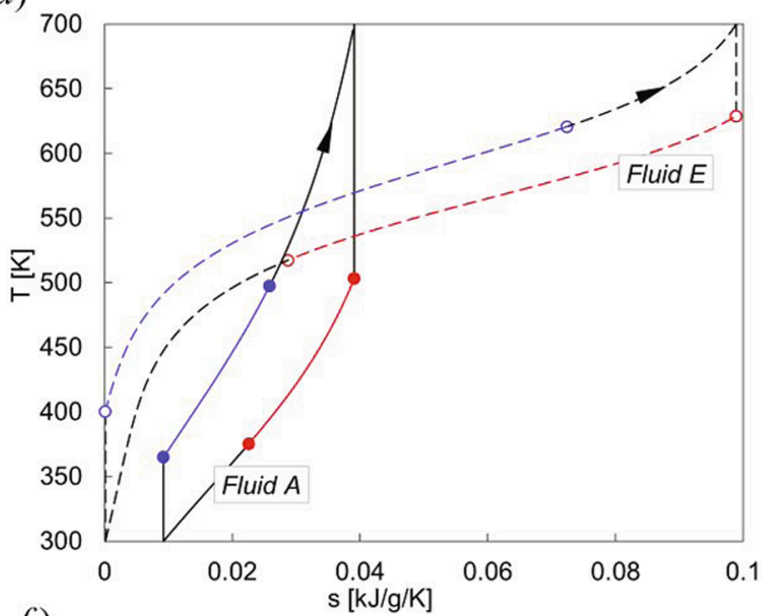

f)

$0.006 \frac{\text { ₹ }}{\frac{\Sigma}{\circ}}$

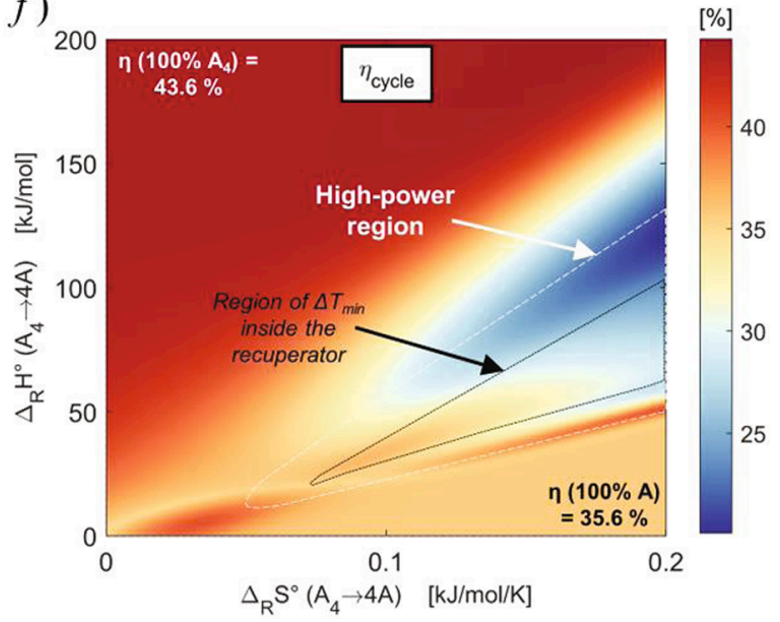

Fig. 6. The efficiency of thermo-chemical engines working with various fluids, and factors which limit the achievement of higher efficiencies. Fig. a: Efficiency map for the working fluid $\mathrm{A}_{2} \rightleftarrows 2 \mathrm{~A}$. Fig. b: Map showing the variation of the ratio between the thermal power recovered in the recuperator and the total thermal power required to heat the fluid from the compressor outlet to the turbine inlet. Fig. c: Temperature profiles of the hot and cold streams crossing the recuperator of three cycles operating with three different working fluids of type $A_{2} \rightleftarrows 2 A$; with respect to Fig. a: fluid A (continuous line), fluid D (dotted line), fluid $E$ (dashed line). Fig. d: Temperature-entropy diagrams of cycles resulting from the use of fluid A (continuous line) and fluid $\mathrm{E}$ (dashed line). Fig. e: Temperature profiles in the recuperator of a cycle operating with a fluid of coordinates $\left(\Delta_{\mathrm{R}} \mathrm{S}^{\circ}, \Delta_{\mathrm{R}} \mathrm{H}^{\circ}\right)=(0.2 \mathrm{~kJ} / \mathrm{mol} / \mathrm{K}, 200 \mathrm{~kJ} / \mathrm{mol})$. Fig. f: Efficiency map for the working fluid $\mathrm{A}_{4} \rightleftarrows 4 \mathrm{~A}$. Operating conditions considered to trace Fig. a-d, $f$ are $\mathrm{T}_{\text {max,cycle }}=700 \mathrm{~K}, \mathrm{~T}_{\mathrm{min}, \mathrm{cycle}}=300 \mathrm{~K}, \mathrm{P}_{\text {min,cycle }}=1 \mathrm{bar}, \beta=\mathrm{p}_{\max , \text { cycle }} / \mathrm{p}_{\text {min,cycle }}=3$. In Fig. e, the maximum temperature is $1200 \mathrm{~K}$.

power output (which remains $27 \%$ higher than that of $\mathrm{A}_{2}$-based cycles). If this comparison is performed considering A-based cycles (more powerful but less efficient), the work of reactive F-type fluids is found to be lower $(-18 \%)$, but the efficiency is found to be much higher $(+27 \%)$.
- Reactive fluids leading to the highest power (for example, fluid E), $141 \%$ higher than those attainable with the use of the most powerful pure fluid (molecule A), are characterized by the lowest efficiency ( $-32 \%$ than A-based cycles). 
Table 1

Power and efficiency of thermo-chemical engines operating with different working fluids at $\mathrm{T}_{\max }=700 \mathrm{~K}, \mathrm{~T}_{\min }=300 \mathrm{~K}$ and $\beta=3$.

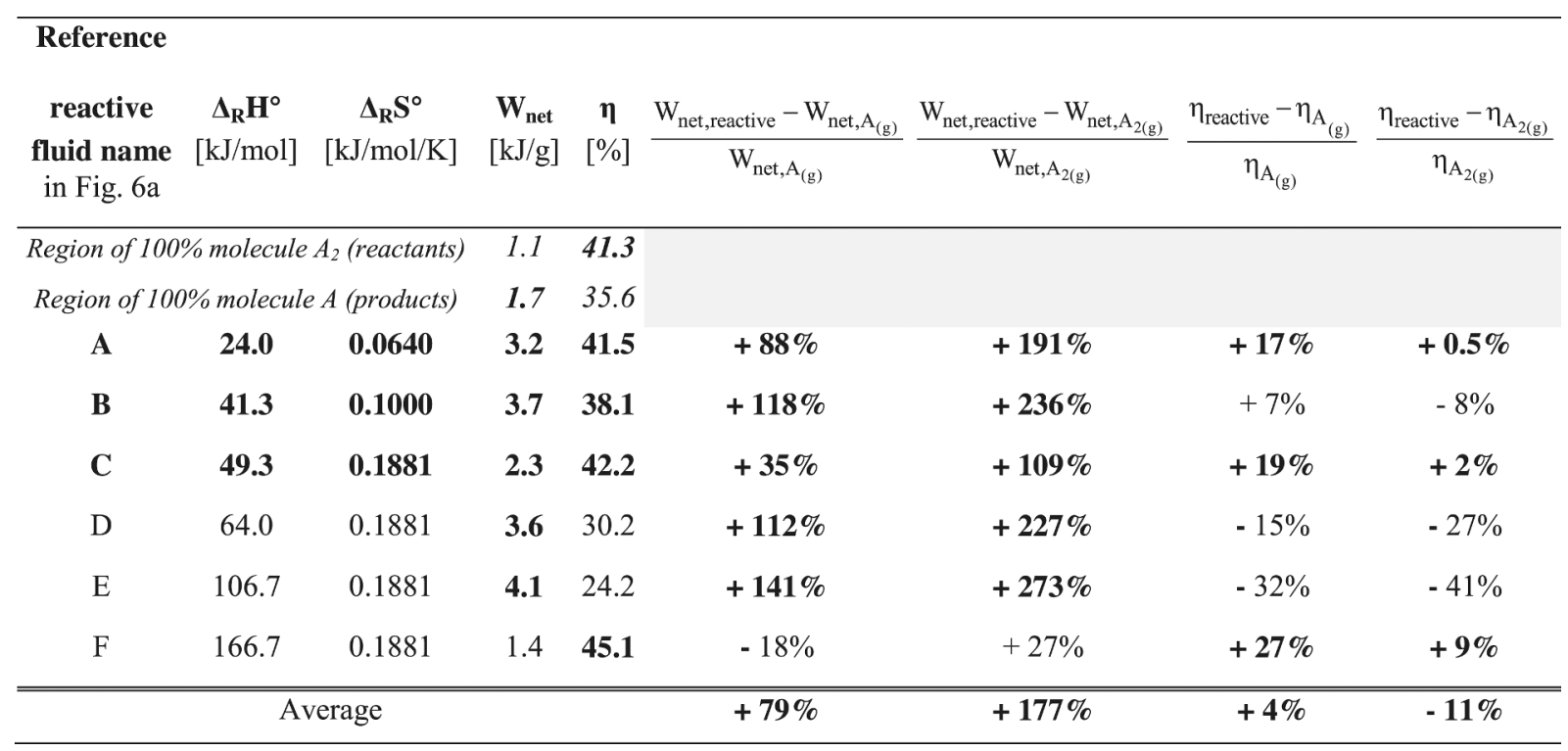

- Reactive fluids (of types A and C) exist that lead to higher efficiencies and higher power than those of any comparable pure fluid. The numerical values reported in Table 1 show that, in any case, the higher is the increase in power output (ranging between 35\% and $191 \%$ ), the lower is the increased efficiency (ranging between $2 \%$ and 19\%).

Reactive fluids leading to the highest power (enclosed by the white dotted line in Fig. 6a) allow the achievement of an acceptable efficiency if the thermal power recovered by the recuperator is sufficiently high. This is revealed by the joint observation of Fig. $6 \mathrm{a}$ and b. However, the maximum recovered thermal power (and thus the achievement of higher efficiencies) is limited by the occurrence of a minimum temperature difference between the two streams occurring inside the recuperator. Fig. $6 \mathrm{c}$ shows temperature profiles in the recuperator of cycles operating with the less efficient fluids $\mathrm{D}$ and $\mathrm{E}$ or with the more efficient (but less powerful) fluid $A$. It can be observed that the higher the enthalpy of reaction of the fluid $\left(\Delta_{\mathrm{R}} \mathrm{H}^{\circ}{ }_{\mathrm{A}}<\Delta_{\mathrm{R}} \mathrm{H}^{\circ}{ }_{\mathrm{D}}<\Delta_{\mathrm{R}} \mathrm{H}^{\circ}{ }_{\mathrm{E}}\right)$, the less efficient is the heat exchange and the higher are the temperature differences between the streams. For a more thorough visualization of the effect of the chemical reaction on the thermodynamic properties of the streams, Tentropy diagrams of cycles based on the use of fluids A and $\mathrm{E}$ are shown in Fig. 6d. Let us consider a more severe utilization of the recuperator (Fig. 6e) in a cycle working with a maximum temperature of $1200 \mathrm{~K}$ instead of $700 \mathrm{~K}$ and a working fluid having reaction coordinates $\Delta_{\mathrm{R}} \mathrm{S}^{\circ}=0.2 \mathrm{~kJ} / \mathrm{mol} / \mathrm{K}$ and $\Delta_{\mathrm{R}} \mathrm{H}^{\circ}=200 \mathrm{~kJ} / \mathrm{mol}$. Fig. 6e shows that if in a portion of the recuperator (the region highlighted in red) one of the two streams is the site of a reaction while the other behaves as an inert fluid, the exchanged heat has a different impact on the temperature profiles of the two streams: the temperature of the stream behaving as an inert fluid (the cold one, in this case) undergoes an important change while the temperature of the fluid behaving as a reactive mixture (the hot one) is much less modified. Indeed, the heat exchanged is given by the sum of a term related to its non-reactive transformation (proportional to the temperature change of the stream) and of a term related to the occurrence of the reaction (proportional to the compositional change of the stream by means of the standard enthalpy of reaction). Fig. 6e also shows that the temperature difference between the two streams is the lowest inside the recuperator if the variation in their extent of reaction with temperature is coincident. If both streams behave either as inert fluids or as reactive fluids characterized by a similar variation in the extent of reaction with temperature, the temperature differences between the two profiles remain acceptably small during heat exchange. Having two streams with the same reaction coordinates, their different thermo-chemical behaviour follows from their different operating conditions: the more different are their operating temperature and pressure conditions, the more the evolution of the reaction differs, giving rise to poor thermal integration in the recuperator. This also partially explains why the use of more dissociating reactions (for example, $\mathrm{A}_{4(\mathrm{~g})} \rightleftarrows 4 \mathrm{~A}_{(\mathrm{g})}$ instead of $\mathrm{A}_{2(\mathrm{~g})} \rightleftarrows 2 \mathrm{~A}_{(\mathrm{g})}$ ) results in lower efficiencies (see Fig. $6 \mathrm{f}$ ).

\subsection{Considering other operating conditions}

The current use of gas power cycles to exploit high-temperature renewable energies (such as solar energies at more than $700 \mathrm{~K}$ ) is usually penalized by the high temperature that characterizes the cold sink (usually ambient air higher than $315 \mathrm{~K}$ ), which might lead to a very low output power. Fig. $7 \mathrm{a}$ and $\mathrm{b}$ show that reactive fluids (for example, fluids of coordinates A1) still allow the achievement of higher power $(+168 \%$, with respect to products, inert molecules $\mathrm{A}$ ) and comparable efficiency for minimum temperatures of $350 \mathrm{~K}$ (which is an extremely high minimum temperature for power cycles).

This theoretical study has shown that the use of proper reactive fluids is also highly convenient at low maximum temperatures. With reference to this point, it is worth highlighting that state-of-the-art gas turbines are renowned for the negative net work they provide at low maximum temperatures (lower than $550 \mathrm{~K}$ ) [8,35]. The use of reactive fluids has also been examined considering a maximum temperature of $400 \mathrm{~K}$, which is a very low temperature characterizing heat sources currently exploitable with very inefficient technologies [3]. Fig. 7c-f shows the simultaneous enhancement of power output and efficiency resulting from the use of reactive fluids in the favourable regions where fluids $A 2$ and $A 3$ lie. Additionally, it can be noted that a reduction in the pressure ratio leads to a decrease in net power while enhancing the efficiency. It is worth observing that the maximum achievable efficiency is the Carnot efficiency, equal to $25 \%$ for hot source and cold sink temperatures equal to $400 \mathrm{~K}$ and $300 \mathrm{~K}$, respectively. Such an extremely high achievable net work and significant efficiency with a low pressure ratio would entail a considerable reduction in the size and costs of thermal engines, on the one hand, and of the system providing the input thermal energy, on the other hand. 

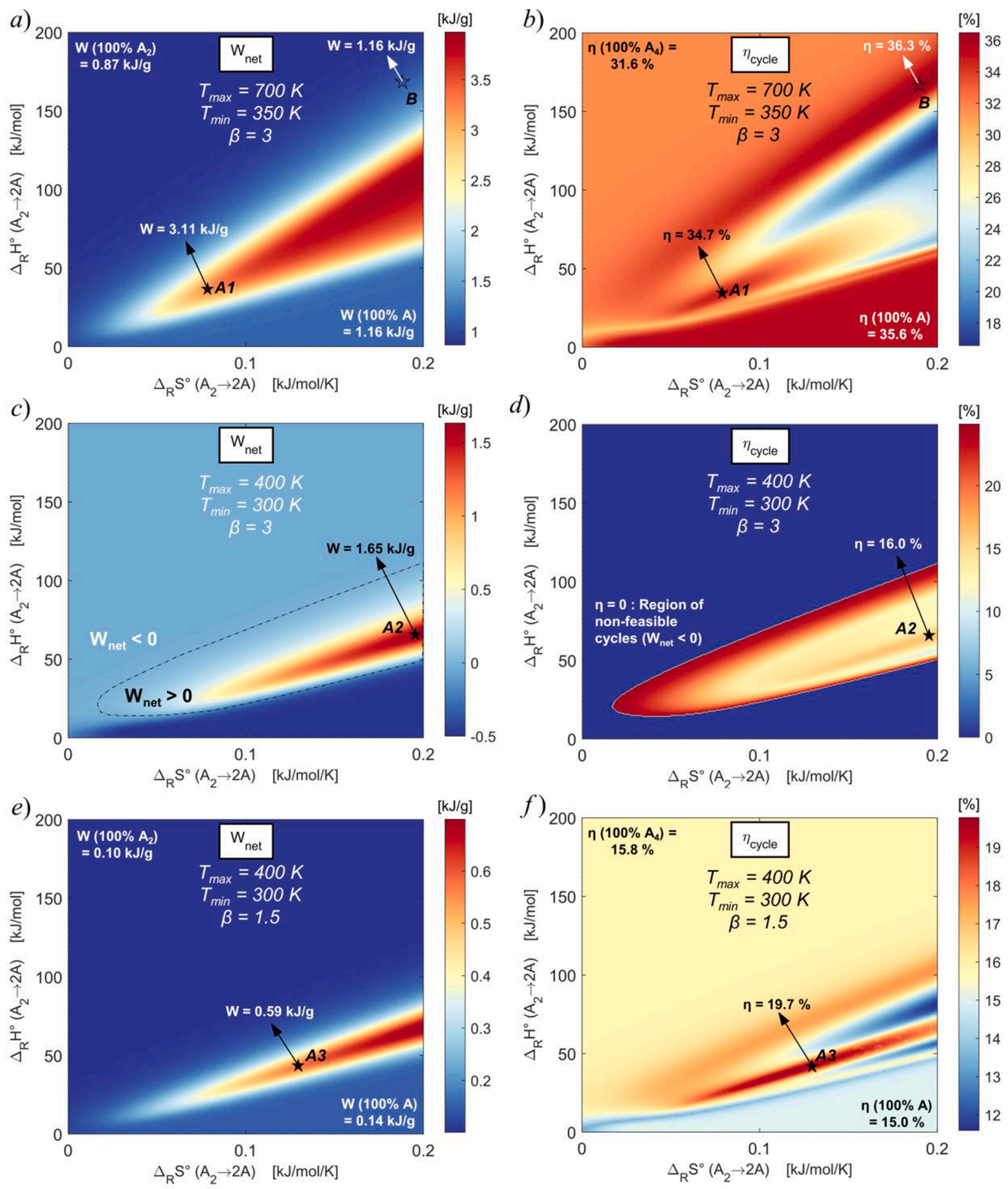

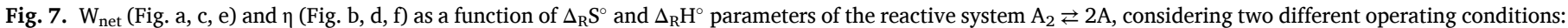

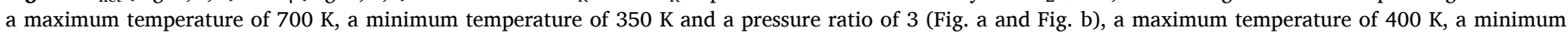

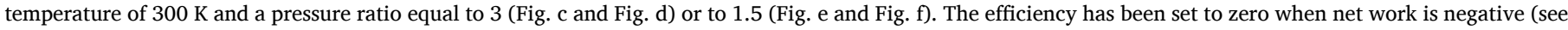
blue region in Fig. d). (For interpretation of the references to colour in this figure legend, the reader is referred to the web version of this article.)

\section{Conclusions}

This work presents the theoretical investigation of a breakthrough idea for producing mechanical energy, exploiting the simultaneous transformation of thermal and chemical energy of equilibrated reactive fluids by means of typical closed gas power cycles.

An original methodology is proposed to enable understanding the effect of thermal and stoichiometric features of reactions on engineproduced power and efficiency. This work demonstrates that, and explains why, the use of specific reactive fluids (i.e., characterized by specific stoichiometric and thermal characteristics) enables the simultaneous maximization of the work generated by their expansion and a minimization of the work required for their compression, thus resulting in an extremely high net work. Indeed, the use of these fluids enables the occurrence of both an exothermic reaction during expansion and an endothermic reaction during compression. Such physicochemical transformations entail the respective heating of the fluid under expansion and cooling under compression, allowing the simple realization of near-isothermal expansion and compression that state-of-the-art thermal engines strive to achieve even with complex technological 
arrangements.

Furthermore, it is demonstrated that, contrary to inert working fluids, properly selected reactive fluids allow obtaining the best performances at extremely low and cost-effective pressure ratios. Moreover, thermo-chemical engines are proven here to potentially enable the simultaneous achievement of high efficiency and high power even for applications (low-temperature heat sources or high-temperature cold sinks) in which optimized inert fluid cycles present either low efficiency and acceptable net work (Rankine cycles) or acceptable efficiency but near zero net work (gas power cycles).

Beyond the presented high potential of thermo-chemical engines, it has been revealed that the proposed recuperative Brayton cycle configuration is not optimal since the thermal power recovered in the recuperator is limited by the configuration itself.

A thus consolidated belief of the authors of this research work is that such promising preliminary results deserve the establishment of a multidisciplinary research line, aiming to make substantial progress towards the validation and improvement of a technology that could potentially allow achieving more efficient and powerful conversion of any available thermal energy source.

\section{CRediT authorship contribution statement}

Silvia Lasala: Conceptualization, Methodology, Software, Data curation, Formal analysis, Visualization, Investigation, Writing - original draft, Project administration. Romain Privat: Conceptualization, Software, Data curation, Formal analysis, Writing - review \& editing, Supervision. Olivier Herbinet: Investigation, Writing - review \& editing. Philippe Arpentinier: Resources, Project administration, Supervision. Davide Bonalumi: Formal analysis, Investigation, Writing - review \& editing. Jean-Noël Jaubert: Conceptualization, Methodology, Formal analysis, Writing - review \& editing, Project administration, Supervision.

\section{Declaration of Competing Interest}

The authors declare that they have no known competing financial interests or personal relationships that could have appeared to influence the work reported in this paper.

\section{References}

[1] British Petroleum Company. BP Statistical Review of World Energy. London: 2019

[2] IEA. Renewables Information 2019. IEA, Paris: 2019.

[3] Quoilin S, Broek MVD, Declaye S, Dewallef P, Lemort V. Techno-economic survey of Organic Rankine Cycle (ORC) systems. Renew Sustain Energy Rev 2013;22: 168-86. https://doi.org/10.1016/j.rser.2013.01.028.

[4] IRENA, C2E2. Synergies between renewable energy and energy efficiency. IRENA, Abu Dhabi and C2E2, Copenhagen: n.d.

[5] IRENA. Renewable Power Generation Costs in 2018. International Renewable Energy Agency, Abu Dhabi: 2019.

[6] Invernizzi CM. Closed Power Cycles: Thermodynamic Fundamentals and Applications. London: Springer-Verlag; 2013. https://doi.org/10.1007/978-14471-5140-1.

[7] Gülen SC. Gas Turbines for Electric Power Generation. Camb Core 2019.
[8] Astolfi M, Alfani D, Lasala S, Macchi E. Comparison between ORC and CO2 power systems for the exploitation of low-medium temperature heat sources. Energy 2018;161:1250-61. https://doi.org/10.1016/j.energy.2018.07.099.

[9] Lighthill MJ. Dynamics of a dissociating gas. Part I: Equilibrium flow. J Fluid Mech 1957;2:1-32

[10] Jacobs TA, Lloyd JR. The Influence of the Equilibrium Dissociation of a Diatomic Gas on Brayton-Cycle Performance. J Appl Mech 1963:288-90.

[11] Cheung H. Dissociating gas as a working fluid for space plant. Energy Convers 1968;8:125-8.

[12] Krasin AK, Nesterenko VB. Dissociating gases: a new class of coolants and working substances for large power plants. At Energy Rev 1971;9:177.

[13] Sikorin S, Mandzik S, Polazau T, Hryharovich T, Tukhvatulin SH, Daragan I, et al. The shipment of Russian-origin highly enriched uranium spent and fresh nuclear fuel from Belarus and delivery of fresh low enriched uranium nuclear fuel to Belarus. RERTR 2011 - 33rd Int. Meet. Reduc. Enrich. Res. Test React., Santiago, Chile: 2011.

[14] Bradley WJ. Recouping the thermal-to-electric conversion loss by the use of waste heat. Low-Grade Heat Resour. Cold Clim., vol. 2, Chalk River Nuclear Laboratories: 1976 , p. $535-58$.

[15] Sorokin A. Dissociating Nitrogen Dioxide (N2O4) as a working fluid in thermodynamic cycles. Nucl Sci Eng 1979;72:330-46.

[16] Angelino G. Performance of N2O4 gas cycles for solar power applications. Proc Inst Mech Eng 1847-1982 Vols 1-196 1979;193:313-20. https://doi.org/10.1243/ PIME_PROC_1979_193_033_02.

[17] Kesavan K, Osterle JF. Split-Flow Nuclear Gas Turbine Cycle Using Dissociating N2O4. American Society of Mechanical Engineers Digital Collection 1982. https:// doi.org/10.1115/82-GT-181.

[18] Kesavan K. The use of dissociating gases as the working fluid in thermodynamic power conversion cycles. Carnegie-Mellon University; 1978.

[19] Kesavan K, Osterle JF. Brayton cycle using dissociating nitrosyl chloride 1981: 2204-9.

[20] Huang HM, Govind R. Use of Dissociating Gases in Brayton Cycle Space Power Systems. Ind Eng Chem Res 1988;27:803-10.

[21] Huang H-M, Govind R. Optimisation of powerplants using dissociating gases as working fluids. Proc. 20th Intersoc. Energy Convers. Eng. Conf., vol. 3, Warrendale, PA 15096: 1985, p. 620-9.

[22] Huang H-M, Govind R. Studies on power plants using dissociating gases as working fluids. Chem Eng Comm 1988;72:95-119.

[23] Manzolini G, Binotti M, Bonalumi D, Invernizzi C, Iora P. CO2 mixtures as innovative working fluid in power cycles applied to solar plants. Techno-economic Assess Sol Energy 2019;181:530-44. https://doi.org/10.1016/j. solener.2019.01.015.

[24] Binotti M, Invernizzi CM, Iora P, Manzolini G. Dinitrogen tetroxide and carbon dioxide mixtures as working fluids in solar tower plants. Sol Energy 2019;181: 203-13. https://doi.org/10.1016/j.solener.2019.01.079.

[25] Blander M. Aluminum Chloride as a Thermodynamic Working Fluid and Heat Transfer Medium. Oak Ridge National Laboratory; 1959.

[26] Gyftopoulos EP, Beretta GP. Thermodynamics - Foundations and Applications. 2005.

[27] Callen HB. Thermodynamics and an Introduction to Thermostatistic. 2nd ed. Inc: John Wiley \& Sons; 1985.

[28] Smith JM, Ness HCV, Abbott MM. Introduction to Chemical Engineering Thermodynamics. 7 ed. Boston: McGraw-Hill Education; 2004.

[29] Althaus E, Jakubith M. Memofix - Chemistry and Chemical Engineering. Weinheim; New York: Wiley VCH; 1993.

[30] Hummel W, Filella M, Rowland D. Where to find equilibrium constants? Sci Total Environ 2019;692:49-59. https://doi.org/10.1016/j.scitotenv.2019.07.161.

[31] Incropera FP, DeWitt DP, Bergman TL, Lavine AS. Fundam Heat Mass Transfer 2007; vol. 6th.

[32] van't Hoff JH. Etudes de dynamique chimique. Amsterdam : Frederik Muller; 1884.

[33] Lasala S, Privat R, Jaubert J-N. Inert and reactive working fluids for closed power cycles: present knowledge, applications and open researches. In: Wang E, editor. Org. Rank. Cycle Technol. Heat Recovery, InTech; 2018. https://doi.org/10.5772/ intechopen.79290.

[34] Moran MJ, Shapiro HN, Boettner DD. Fundamentals of Engineering Thermodynamics. 7th ed. Wiley Global Education; 2010.

[35] Macchi E, Astolfi M. Organic Rankine Cycle (ORC) Power Systems: Technologies and Applications. Woodhead Publishing; 2016. 